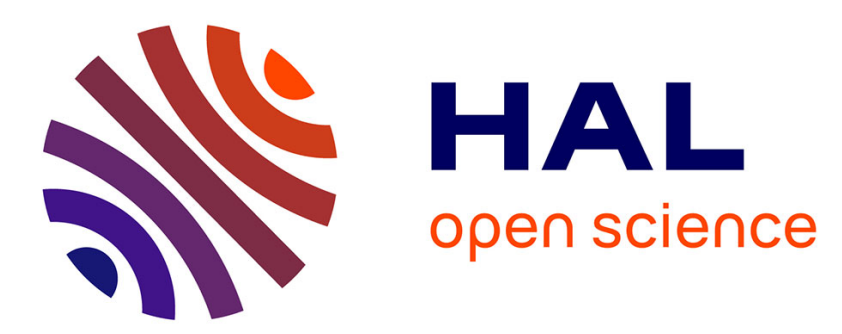

\title{
Loading Rate Dependence of the Deformation and Fracture Mechanisms in Impact Modified Poly(Methyl Methacrylate) \\ P. Béguelin, H. Kausch
}

\section{- To cite this version:}

P. Béguelin, H. Kausch. Loading Rate Dependence of the Deformation and Fracture Mechanisms in Impact Modified Poly(Methyl Methacrylate). Journal de Physique IV Proceedings, 1997, 07 (C3), pp.C3-933-C3-938. 10.1051/jp4:19973157 . jpa-00255446

\section{HAL Id: jpa-00255446 \\ https://hal.science/jpa-00255446}

Submitted on 1 Jan 1997

HAL is a multi-disciplinary open access archive for the deposit and dissemination of scientific research documents, whether they are published or not. The documents may come from teaching and research institutions in France or abroad, or from public or private research centers.
L'archive ouverte pluridisciplinaire HAL, est destinée au dépôt et à la diffusion de documents scientifiques de niveau recherche, publiés ou non, émanant des établissements d'enseignement et de recherche français ou étrangers, des laboratoires publics ou privés. 
J. PHYS IV FRANCE 7 (1997)

Colloque C3, Supplément au Journal de Physique III d'août 1997

\title{
Loading Rate Dependence of the Deformation and Fracture Mechanisms in Impact Modified Poly(Methyl Methacrylate)
}

\author{
P. Béguelin and H.H. Kausch \\ EPFL Laboratoire de Polymères, MX-D, 1015 Lausanne, Switzerland
}

\begin{abstract}
The tensile and fracture properties of rubber toughened poly(methylmethacrylate) (rtPMMA) modified by spherical core-shell particles, and poly(urethane)/poly(methyl methacrylate) (PU/PMMA) interpenetrating polymer networks (IPN) are investigated at different strain rates. The deformation and fracture mechanisms are studied by transmission electron microscopy (TEM). The results of the tensile tests show that deformation in both rtPMMA and IPN involves cavitation. The amount of cavitation increases with the strain rate in both kinds of material. This leads to similar mechanical properties in each case, and shows that a spherical particle morphology is not prerequisite for cavitation. A phenomenological model of the micromechanisms of deformation in core-shell particle modified PMMA is proposed.

Résumé: Nous avons étudié les propriétés en traction et en rupture sur une large plage de vitesse des polyméthacrylates de méthyle modifiés au choc (rtPMMA). Des matrices PMMA modifiées par des particules sphériques à noyau dur et à écorce molle sont comparées avec un réseau de polymères interpénétrés (IPN) polyuréthanne /polyméthacrylate de méthyle (PU/PMMA). Les mécanismes de déformation et de rupture sont étudiés par microscopie électronique à transmission. Les résultats des essais de traction montrent que des mécanismes de déformation par cavitation sont impliqués dans ces deux types de matériaux. La cavitation augmente lorsque la vitesse de déformation est augmentée. Les propriétés mécaniques sont ainsi comparables, et on conclut qu'une morphologie sphérique de la phase modificatrice n'est pas nécessaire pour initier les mécanismes de cavitation. Enfin, un modèle phénoménologique est proposé pour expliquer la nature des micromécanismes de déformation.
\end{abstract}

\section{INTRODUCTION}

A significant increase of the impact properties of amorphous brittle polymers can be achieved by incorporating a rubbery phase in the matrix. Spherical particles are often mechanically incorporated during the processing of the material. In commercialised systems, these particles consist either of soft rubbery spherical particles or by a hard glassy core surrounded by a soft rubbery shell. To insure the compatibilisation with the matrix, both types of particles are usually surrounded by a hard external shell grafted to the rubbery phase.

The impact modification of (PMMA) by the mechanical blending of a low molecular weight PMMA with rubbery particles can be achieved only by a process involving shear deformation such as extrusion or injection moulding. Since shear deformation is not present in the casting process of acrylic resins which is also a common way to produce plates of such materials, in-situ polymerised casting of interpenetrating polymer networks (IPN) is another way to elaborate rubber toughened materials. The impact properties of such materials are controlled by the fraction of rubbery phase and its morphology. Heim et al . [1] found a significant improvement of the properties by incorporating only $5-6 \%$ of polyurethane (PU) as secondary phase. The morphology of this rubbery phase appears to be highly dependent of the kinetics of polymerisation during the network formation. In this study, we have compared the mechanical behaviours of this Poly(urethane)/Poly(methyl methacrylate) (PU/PMMA) interpenetrating networks with some PMMA modified by core-shell particles.

\section{MATERIALS}

The two core-shell particle modified PMMAs investigated here are industrially produced materials. The particles are prepared by emulsion polymerisation and consist of an inner glassy core of PMMA, surrounded by a rubbery shell based on Poly $(n$ Butyl Acrylate-co-Styrene $)$. An outer layer of PMMA 


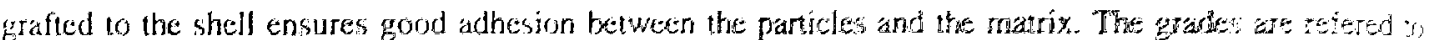

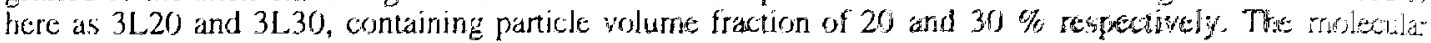
weight of the matrix is close to $1300^{2}$ (f) $(x) \mathrm{g} / \mathrm{mol}$.

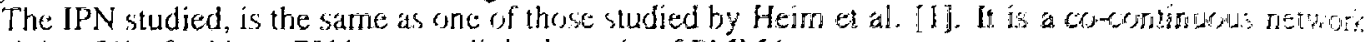
containing $5 \%$ of rubbery PI in a crosslinked matrix of PMMA.

\section{EXPERIMENTS}

In order to distinguish the different processes contributing to the overall tensile deformationn, Iow rate experiments ( 2 to $200 \mathrm{~mm} / \mathrm{min}$ ) have been performed at room temperature on 3L30 and IPN. The volume change during the deformation process has been measured, using simultaneous longitudimal ard lateral extensometry, following the approach proposed by Frank and Lehmann in 1986 [2]. The elastic strain, $\varepsilon_{\text {viss, }}$ has been calculated assuming that the overall elastic modulus, $E$, does not change significantly during the deformation process. Using the same assumption, the permanent cavitational strain, $\varepsilon_{s, w}$, was calculated by the following relation:

$$
\varepsilon_{\text {cav }}=(1+\varepsilon)\left(1+\varepsilon_{\text {lat }}\right)^{2}-1-\varepsilon_{\text {elaus }}\left(1-2 v_{\text {elast }}\right)
$$

where $\varepsilon$ is the longitudinal strain, $\varepsilon_{\text {lat }}$, the lateral strain and, $v_{\text {elass }}$, the Poisson's ratio measured in the elastic region.

The shear strain, $\varepsilon_{\text {shear }}$ was taken to be the non-elastic and non-cavitational strain, such that:

$$
\varepsilon_{\text {shear }}=\varepsilon-\varepsilon_{\text {elast }}-\varepsilon_{\text {cav }}
$$

Fracture mechanics experiments on these three materials, at testing speeds between $10^{-4}$ and $10 \mathrm{~m} / \mathrm{s}$ were conducted on compact tension (CT) specimens, using the experimental approach developed in our laboratory $[3,4]$. The critical stress intensity factors, $K_{I C}$, have been calculated from the maximum of force. The energy used to calculate the critical energy release rate at initiation, $\mathrm{G}_{\mathrm{IC}}$, was obtained by integrating the force-displacement curves up to the maximum of force.

\section{RESULTS}

\subsection{Tensile experiments}

It is well known that stress whitening occurs when rtPMMA modified by spherical particles is strained. It is more surprising that the same effect is observed in PU/PMMA interpenetrating polymer networks. It has been clearly established by in-situ optical measurements of this phenomenon that stress whitening can be detected at very low strains (about $1 \%$ ), but increases drastically near the yield point of the stress-strain curve [3] in both materials.

Our volume strain measurements during tensile experiments (see Figure 1) show that for both type of materials, the permanent cavitational strain detectable using this approach, occurs at the apparent vield strair. of the materials. Thus, cavitation is closely related to the overall yielding of the material. In this regime of strain rates, the amont of permanent cavitational strain increase with the strain rate. Therefore, dilatationa deformation mechanisms occur with both types of morphologies of the modifying phase. and one can conclude that a spherical morphology of the rubbery phase is not necessary to induce cavitational strain in the material.

\subsection{Fracture}

Compared with approaches in which only one or two testing speeds are used, the use of a wide range $c^{:}$ testing velocities, $v$, in fracture experiments gives a more complete picture of the fracture betwiour of the materials. The results are shown in Figure 2. Although no tough to britle transitions are found at high.

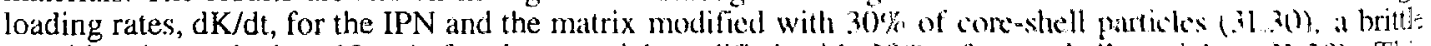

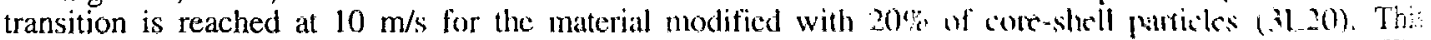
transition is clearly seen when considering the critical stress intensity factor. $K_{10}$. shown in figure 2 a. Th: 


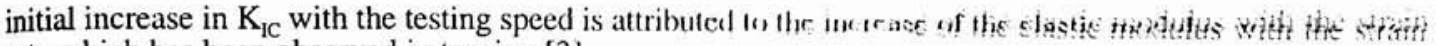
rate which has been observed in tension [3].

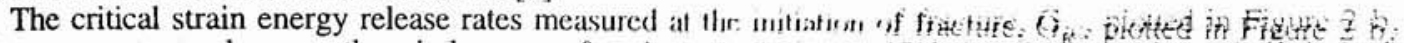

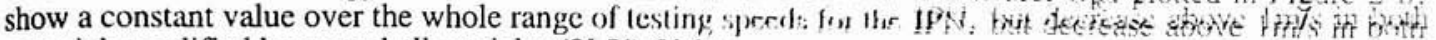
materials modified by core shell particles (3L20, 31.30)

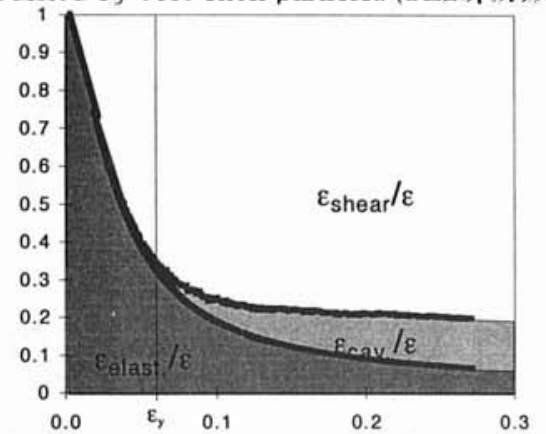

a)

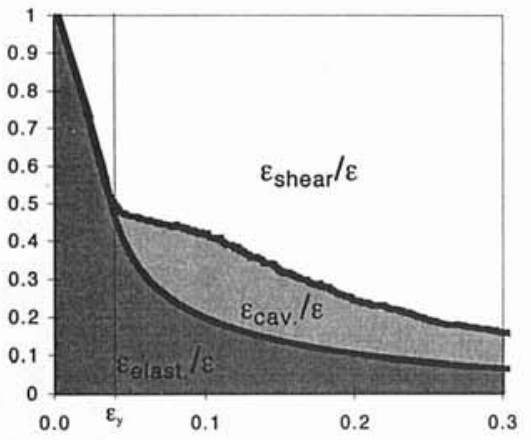

c)

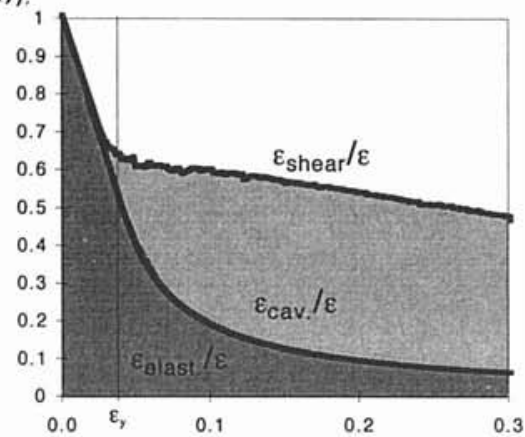

$\varepsilon(-)$

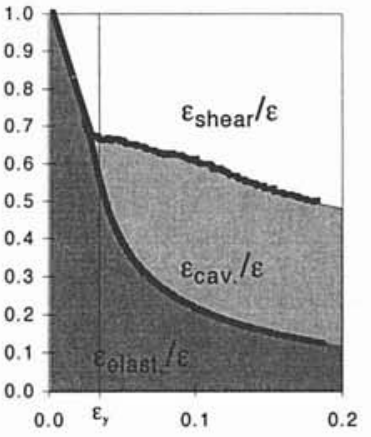

$\varepsilon(-)$

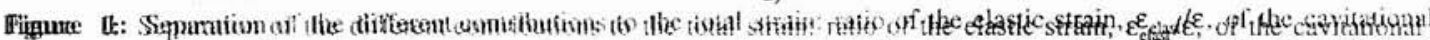

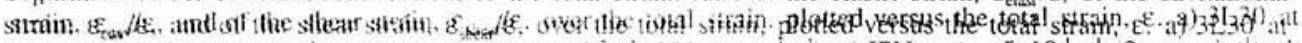

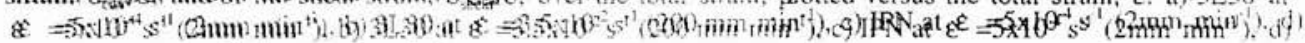

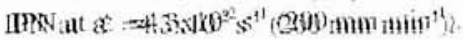
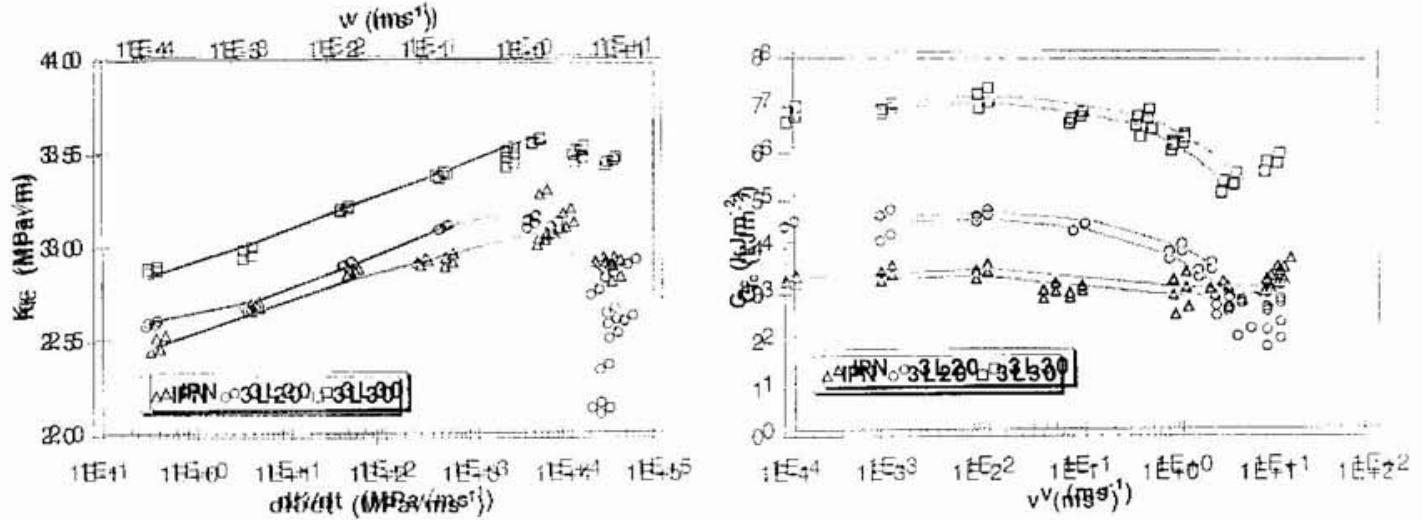

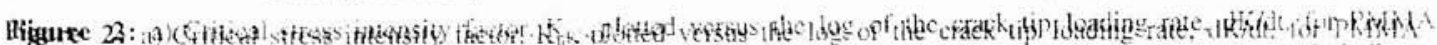

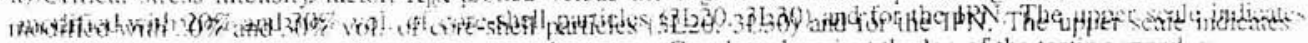

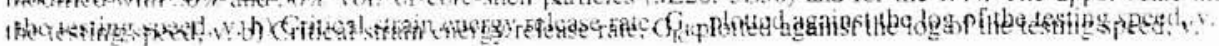


From a fractographic point of view, it is relevant to mention that the stabilisation of $\mathrm{K}_{\mathrm{tC}}$ and the decrease of $\mathrm{G}_{\mathrm{IC}}$ found at high loading rates in the $3 \mathrm{~L} 30$ and $3 \mathrm{~L} 20$ occurs when partially unstable fracture is observed. whercas in the IPN, the crack propagation is stable over the whole range of testing speeds. Furthermore, the brittle transition of the $3 \mathrm{~L} 20$ is associated with the unstable fracture over the entire ligament [5].

\section{TEM OBSERVATIONS OF THE DEFORMATION MECHANISMS}

Microtomed sections of $100 \mathrm{~nm}$ thick were cut from the bulk of $2 \mathrm{~L} 20$ and IPN specimens. The scctions were removed from the crack front arrested after propagation in a stable manner at the testing speed of $10^{\circ}$ $\mathrm{m} / \mathrm{s}$. They werc observed by transmission clectron microscopy (TEM) using a Philips EM 30).

\subsection{Material modified with $20 \%$ of core-shell particles}

Since the surroundings of a crack front offer a complete picture of the strain gradient, it is possible to observe the whole sequence of deformation mechanisns involved in fracture. Figure 3 shows the mechanisms responsible for energy dissipation in the $3 \mathrm{~L} 20$. This material was chosen because the low concentration of particles gives a relatively large interparticle distance, facilitating the observation of the deformation mechanisms in the matrix.

b)

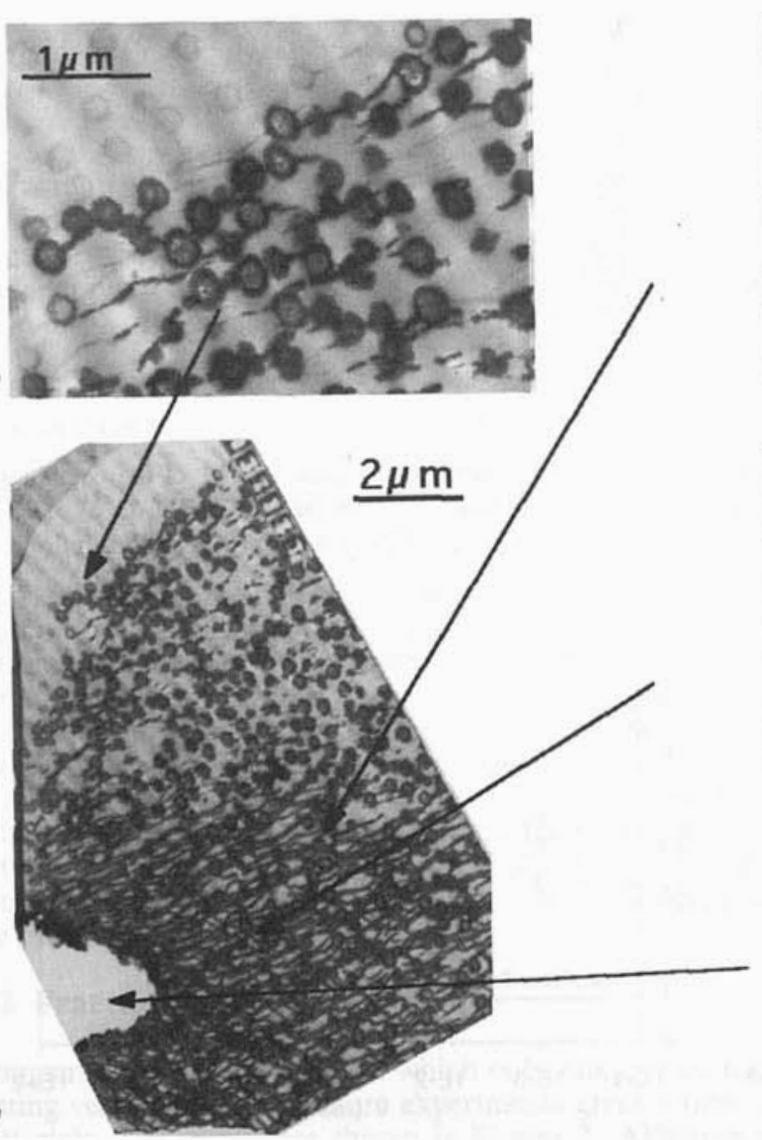

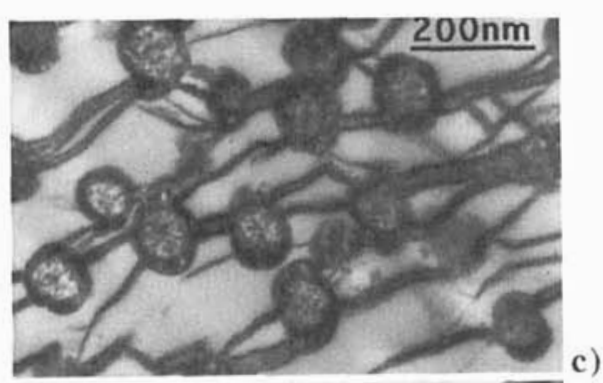
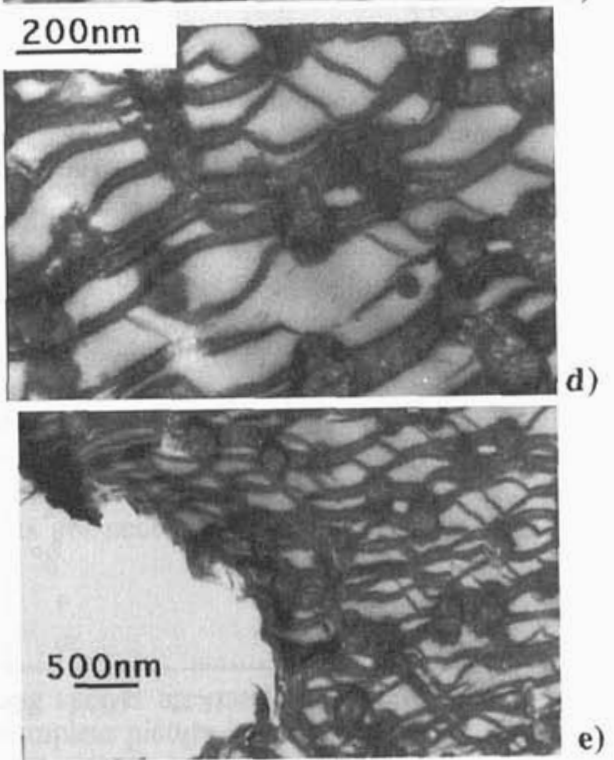

Figure 3: Deformation mechanisms in front of a crack tip in a PMMA modified with 20\% vol. core-shell particles. 


\subsection{Interpenetrating polymer networks PU/PMMA}

Using the same technique, some TEM observations of the crack front in IPN has been performed. They are shown in Figure 4.

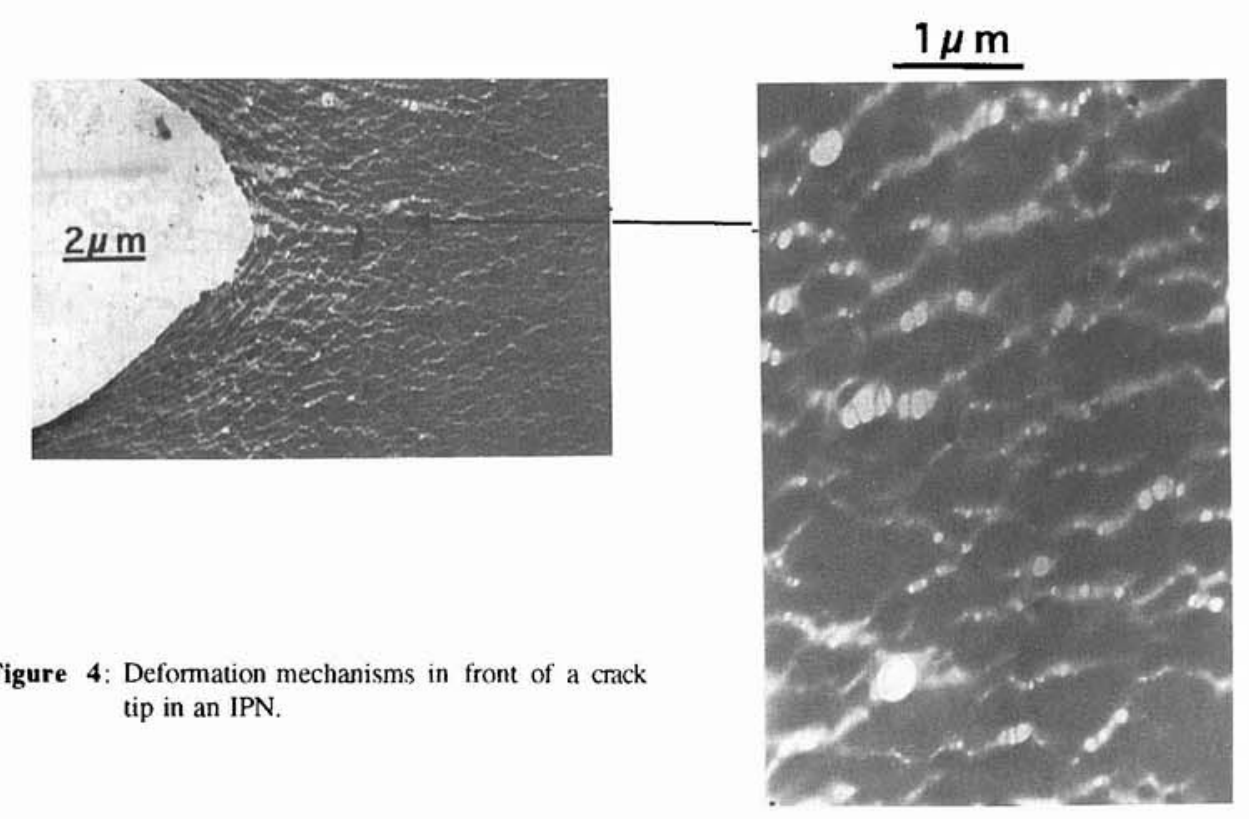

\section{DISCUSSION AND PHENOMENOLOGICAL MODEL}

\subsection{PMMA modified with spherical core-shell type particles}

Based on the TEM observations performed on 3L20, we propose a phenomenological model for the deformation mechanisms in core-shell type modified PMMA. This model shown schematically in Figure 5 explains the damage developpement by three different mechanisms:

- The first damage is initiated by the negative hydrostatic pressure applied to the particies by the remrte stress, and cavities of small size begin to grow in the poles of the rubbery shells of the particles (Figure $3 \mathrm{~b})$. The sudden increase of stress in the matrix surrounding the particles, triggered by the shell cavitation, results in the initiation of crazes at the particle equators. These crazes then propagate in the matrix regions between the particles by a mechanisms of growth at constant stress in the craze fibrils. as in unmodified PMMA(Figure $3 \mathrm{c}$ ).

- Once the crazes penetrate in regions mechanically influenced by neighbouring particles. they deviate frem their initial plane of propagation. In the highly strained region of the crack tip. most of the craze tips split into two new crazes which deviate towards the poles of neighbouring particles (Figure $3 \mathrm{~d}$,

-The crack then propagates by a mechanisms of flow of the matrix (Figure 3 e). Mairix yielding accurs locally. since triaxiality of stress can no longer exist in such small isolated regions of the matrix. linked only by the surrounding craze fibrils.

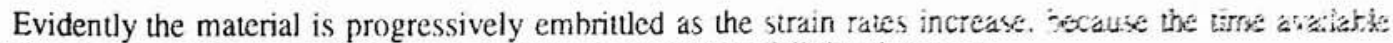
for the above mechanisms becomes too short to permit their full development.

It is not clear yet whether the mechanism of craze splitting is related specifically is the preseroe of ans. shell type particles (as opposed to rubbery corc type particles). which appear is, remain actres in terma $\therefore$

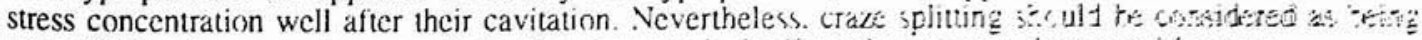
very efficient in terms of energy dissipation, hecause it significantly increases the ares thature. 


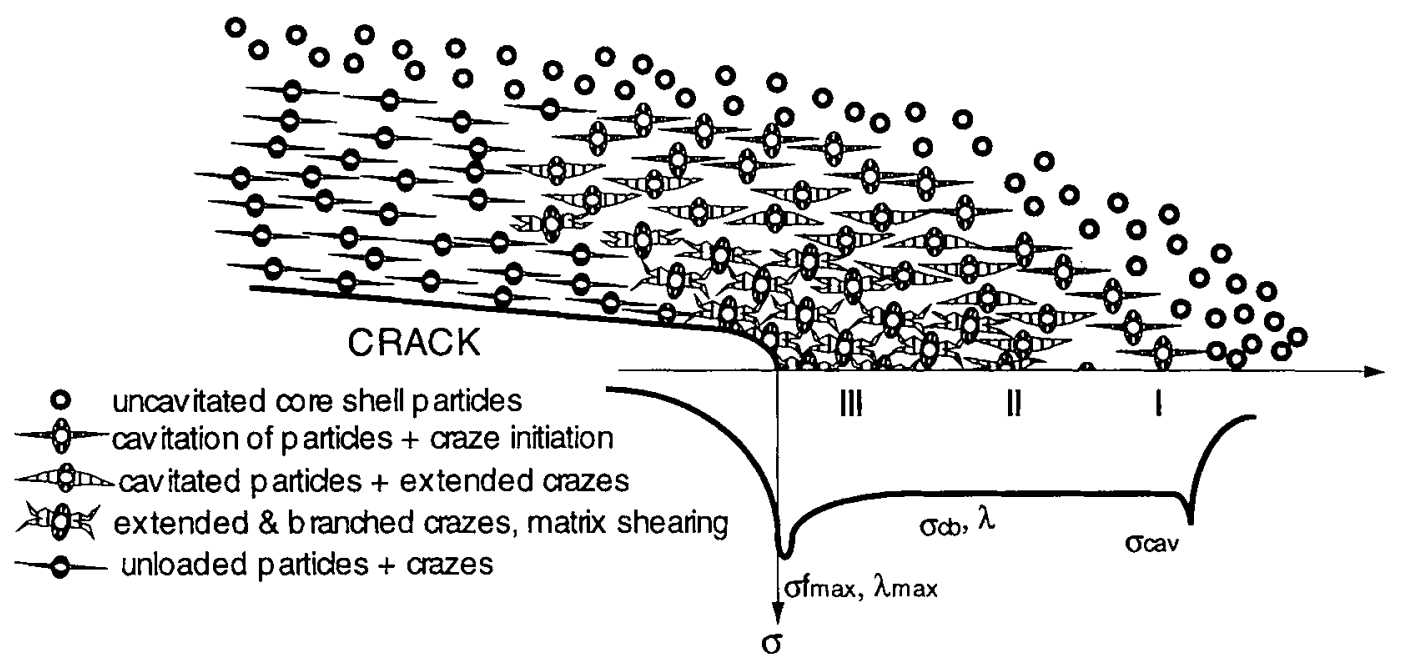

Figure 4: Schematic representation of the deformation mechanisms and the related stress state ahead of the crack tip in a PMMA modified by core-shell type particles.

\subsection{Deformation mechanisms in IPN.}

In the PU/PMMA interpenetrating polymer networks, no craze formation is observed. High magnification TEM observations show that cavitation exists, but is initiated in star-shaped regions of the PU rubbery phase. The volume of the matrix elements isolated by the rubbery ligaments is in the same order of magnitude as that observed in the crazed rtPMMA. Thus, despite its slightly crosslinked structure, similar mechanisms of crack growth by matrix flow can occur. Since the micromechanisms responsible for toughening are governed only by the glass transition temperature of the rubbery phase, it is therefore not surprising that the brittle transition is shifted towards higher strain rates, which were not attained in this study. Furthermore, the lower activation energy of the rubbery phase responsible for toughening in the IPN, compared with that required by craze formation in the glassy matrix of particle modified PMMA. explains the lower fracture energy of the IPN.

\section{CONCLUSIONS}

Comparable toughnesses are observed in PMMA modified by core-shell particles and by a rubbery cocontinuous phase of PU. Although there is cavitation at the network nodes, no crazing in the matrix of the IPN has been observed. Since the dominant dissipative process must be matrix shear deformation in the IPN, it is inferred that shear deformation process must be matrix shear in particle toughened PMMA. As with unmodified PMMA, crack advance will be ultimately determined by the critical break-down stress of the matrix ligaments and/or craze filaments at the crack tip, although stable crack growth will be accompanied by propagation of the whole damage zone, rather than widening of a single craze. The extent of stable crack growth will in turn de dependent on the test conditions, namely the strain rate and the temperature.

\section{References}

[1] Heim Ph., Wrotecki C., Avenel M, Gaillard P., Polymer 34 (1993)

[2] Frank O., Lehmann J., Colloid and Polymer Science 264 (1986)

[3] Béguelin $\mathrm{Ph}$., $\mathrm{PhD}$ thesis No 1572, EPFL, Lausanne (1996)

[4] Béguelin Ph., Fond C., Kausch H.H, Fracture Mechanics at Intermediate Rates of Loading: The Influence of the Acceleration on Compact Tension Tests, EURODYMAT 97, 22-26 September 97, Toledo, Spain.

[5] Julien, O., Béguelin Ph., Monnerie L., Kausch H.H., in 'Toughened Plastics II', Advances in Chemistry Series 252, Riew C.K. \& Kinloch A.J. ed., ACS Washington DC, (1997). 